\title{
A Reforma Trabalhista e os Honorários Advocatícios Sucumbenciais: A mitigação das garantias constitucionais do amplo acesso à jurisdição e da assistência judiciária integral gratuita
}

\author{
Labor Reform and Sucumbential Advocatory Fees: The mitigation of the constitutional guarantees \\ of wide access to jurisdiction and free integral judicial assistance \\ Reforma Laboral Y Tarifas De Defensa Sucumbencial: La mitigación de las garantías \\ constitucionales de amplio acceso a la jurisdicción y asistencia judicial integral gratuita
}

Recebido: 15/02/2021 | Revisado: 21/02/2021 | Aceito: 25/02/2021 | Publicado: 04/03/2021

\author{
Pedro Emílio Amador Salomão \\ ORCID: https://orcid.org/0000-0001-9451-3111 \\ Faculdade Presidente Antônio Carlos, Brasil \\ E-mail: pedroemilioamador@yahoo.com.br \\ Rodrigo Gomes de Castro Vieira \\ ORCID: https://orcid.org/0000-0002-7085-8411 \\ Faculdade Presidente Antônio Carlos, Brasil \\ E-mail: rodrigo.castrog@outlook.com \\ Geovana Silveira Soares Leonarde \\ ORCID: https://orcid.org/0000-0003-3336-4161 \\ Faculdade Presidente Antônio Carlos, Brasil \\ E-mail: geoleonarde@gmail.com
}

\begin{abstract}
Resumo
A presente obra evidencia, a priori, um enfoque amplo acerca dos aspectos básicos inerentes à lei 13.467/2017, conhecida como a Reforma Trabalhista, objetivando a exposição de questões essenciais da desta, e, ainda, nesta temática, demonstra-se a contradição legislativa existente entre as sucintas mudanças legislativas objetivadas pelo projeto de lei que deu origem à lei 13.467/2017 e as reais e inúmeras alterações efetuadas pela Reforma Trabalhista, culminando em variados impactos no direito material e processual trabalhista. De maneira contextual, esta obra expõe, ademais, a colossal incidência dos direitos constitucionais na seara justrabalhista, salientando, mormente, a devida definição e valorosa aplicação dos princípios constitucionais fundamentais do amplo acesso à justiça e da assistência gratuita e integral neste ramo jurídico. Inserindo-se em temática específica, este artigo apresenta o novo artigo 791-A, da CLT, e explicita as graves consequências provocadas por este dispositivo legal sobre o paradigma processual trabalhista, culminando na indevida e nociva mitigação de garantias constitucionais que eram sinal de segurança e proteção jurídica ao jurisdicionado.
\end{abstract}

Palavras-chave: Reforma trabalhista; Princípios constitucionais; Mitigação.

\begin{abstract}
This paper presents, initially, a general approach to the basics aspects concerning 13.467/2017 Llw, as known as the Labor Reform, aiming an exposure of key issues about it and also, still in this same thematic, the demonstration of the legislative contradiction between the succinct changes intended by the bill that gave rise to the 13.467/2017 law and the true and countless changes performed by the Laboral Reform, culminating in many impacts on the material and procedural law. In a contextual way, this work exposes, besides, the huge incidence of the constitutional rights on the labor law reality, focusing, primarily on the definition and valuable application of the constitutional principles of the broad access to justice and free and full juridic assistance among the labor law. On a specific theme, this article presents the new 791-A CLT article and explains the serious consequences provoked by this legal device over the labor procedural paradigm, culminating on the undue and harmful mitigation of the constitutional guarantees that were a sign of security and legal protection to the jurisdiction.
\end{abstract}

Keywords: Labor reform; Constitutional guarantees; Mitigation.

\section{Resumén}

El presente trabajo evidencia, a priori, un amplio enfoque en los aspectos básicos inherentes a la Ley 13.467 / 2017 , conocida como Reforma Laboral, con el objetivo de exponer cuestiones esenciales de esta, y, aún, en este tema, se demuestra la contradicción legislativa entre los sucintos cambios legislativos previstos por el proyecto de ley que dio 
origen a la ley 13.467 / 2017 y los reales y numerosos cambios realizados por la Reforma Laboral, que culminaron en diversos impactos en la legislación laboral material y procesal. De manera contextual, este trabajo expone, además, la colosal incidencia de los derechos constitucionales en el campo justrabalista, destacando, principalmente, la debida definición y valiosa aplicación de los principios constitucionales fundamentales del acceso amplio a la justicia y la asistencia gratuita e integral en esta rama jurídica. Insertando un tema específico, este artículo presenta el nuevo artículo 791-A, de la CLT, y explica las graves consecuencias que esta disposición legal generó sobre el paradigma procesal laboral, culminando en la atenuación indebida y lesiva de garantías constitucionales que fueron signo de seguridad. y protección legal de la jurisdicción.

Palabras clave: Reforma laboral; Principios constitucionales; Mitigación.

\section{Introdução}

Incontestavelmente, o direito material e processual do trabalho desempenha um papel de imensurável importância nacional, e, para sua boa eficácia e aplicação, deve estar em consonância com as demandas e anseios laborais, o que exige os devidos reflexos e atualizações do diploma legal trabalhista. Em 2017, fatídico ano para o universo justrabalhista, a Reforma Trabalhista rompeu incontáveis laços conectivos entre realidade laborativa e a legislação à ela atinente.

Inserido na hodierna esfera trabalhista criada pela referida reforma, um dos dispositivos legais inseridos na legislação do trabalho que mais prejuízo trouxe à classe laborativa é, indubitavelmente, o art. 791-A, que provoca um sentimento inequívoca de insegurança jurídica ao relativizar garantias constitucionais fundamentais nos quais se firmavam incontáveis pleitos trabalhistas.

O debate abordado por esta obra se pauta na evidenciação da magnitude dos preceitos constitucionais e sua necessária aplicação protetiva na integralidade dos ramos do Direito, necessidade, esta, completamente negligenciada dos prejuízos perpetrados pelo referido artigo legal, o qual é de tal modo danoso que influi e altera a própria natureza do direito processual trabalhista.

Pretendendo a prudente elucidação desta discussão concomitantemente o adequado entendimento pelo leitor, mediante vasta pesquisa bibliográfica e prezando pela argumentação dialética, esta obra exporá aspectos geris apresentados pela Reforma Trabalhista de 2017, explicitando as mudanças legislativas por ela causadas e a consequente convergência e impacto nos ditames materiais e processuais do direito do trabalho e, após, valendo-se de interdisciplinaridade jurídica, este artigo demonstrará a conceituação e incidência dos ditames constitucionais na norma justrabalhista, ressaltando a pertinência dos princípios constitucionais do amplo acesso à jurisdição e da assistência jurídica gratuita e judiciária no processo trabalhista, de modo a explicitar a sua inconsequente e incongruente mitigação provinda da reforma trabalhista, especialmente em razão do art. 791-A da CLT, o qual já foi objeto de ação direta de inconstitucionalidade.

\section{Revisão da Literatura}

\subsection{Aspectos gerais da Reforma Trabalhista}

Resultante de ampla discussão com membros do Ministério do Trabalho e com representantes empregados e empregadores, o Projeto de Lei 6.797, alcunhado como Reforma Trabalhista, iniciado no dia 22 (vinte e dois) de dezembro do ano de 2016, que fora encaminhado por Michel Temer, o então Presidente da República, à Câmara dos Deputados não se propunha a modificar demasiado a legislação trabalhista em vigência, de modo que pretendia realizar alterações, retirando ou inserindo disposições, em meros 07 (sete) artigos constantes na Consolidação das Leis Trabalhistas (CLT), sendo tais os artigos 47, 47-A, 58-A,523-A,611-A 634 E 775. Contudo, mística e estranheza encobrem o processo posterior à apresentação do projeto de lei à Câmara pois, de forma inexplicável, o discreto PL, que a priori objetivava atuar na modificação de poucos artigos, foi ampliado pelo deputado Rogério Marinho (PSDV-RN) e passou a incidir, acrescenta ou modificando, 97 (noventa e sete) artigos 
da Consolidação das Leis Trabalhistas (CLT), 03 (três) artigos da Lei 6.019/74, 01 (um) artigo da Lei 8.036/90, 01 (um) artigo da Lei 8.213/91 e 01 (um) artigo da MP 2.226/2001.

Acerca dessas mudanças de paradigmas que revestes as contraditórias alterações ocorridas no interim da Reforma, o professor Carlos Henrique Bezerra Leite, expõe que:

Essa proposta legislativa de reforma trabalhista não se limitou apenas a alterar o texto da CLT. Na verdade, sob o argumento da necessidade da "modernização" das relações trabalhistas, ela institui três princípios de proteção ao Capital (liberdade, segurança jurídica e simplificação), invertendo os valores, os princípios e as regras de proteção ao trabalhador consagrados em diversas normas constitucionais e internacionais (Leite, 2019, p. 44).

Findada a contextualização supra, é natural quedar-se surpreso, abismado, perplexo, ao perceber que o intento de realizar simples mudanças no universo justrabalhista fora transformado "num pacote de cerca de 100 dispositivos de lei que não puderam ser minimamente ajustados ou estudados". Indubitavelmente, o Direito não deve andar em descompasso com as demandas da sociedade, assim, é imprescindível que haja mudança no universo legal, contudo, "mudar mediante uma irrefletida análise das consequências que podem advir dessas mudanças é [...] complicado". Nesse cenário construído pela Reforma Trabalhista de 2017, Vólia Bonfim Cassar entende que:

Tratar de uma reforma legislativa tão profunda, como é a trabalhista, pelos aspectos materiais e processuais, não é uma tarefa simples. A começar pela desconstrução de diversos institutos consagrados pela história brasileira. Mexeu-se com o coração do trabalhador, com os seus sentimentos, com a sua afetividade, com o seu bolso, com a sua vida social enfim. E o que e o pior: com uma legislação que e fruto de diversos casuísmos, não raro mostrando-se atécnica e irrefletida, desconsiderando o verdadeiro cenário da sociedade brasileira (Cassar, 2017, p. 07).

Ante a impactante conjuntura que circunda o Direito e Processo do Trabalho, em momento pós-reforma, grandes nomes que formam a doutrinária nacional adotaram um papel quiçá mais crítico que o atual, de modo que iniciaram uma incansável e honrada jornada que se pauta a expostos os equívocos implementados pela alteração da legislação trabalhista. Com uma precisão cirúrgica, o ilustre Maurício Godinho Delgado, no alvorecer de sua brilhante obra A Reforma Trabalhista no Brasil, expõe que:

Profundamente dissociada das ideias matrizes da Constituição de 1988, como a concepção de Estado Democrático de Direito, a principiologia humanística e social constitucional, o conceito constitucional de direitos fundamentais da pessoa humana no campo justrabalhista e da compreensão constitucional do Direito como instrumento da civilização, a Lei 13.467/2017 tenta instituir múltiplos mecanismos em direção gravemente contrária e regressiva (Delgado, 2017, p. 40).

\subsubsection{Os impactos da reforma no processo trabalhista}

Em âmbito nacional, a sistemática processual do Direito apresenta, de maneira ampla, a chamada Teoria Geral do Processo, a qual é difundida e aplicada em múltiplos ramos jurídicos. De modo a não ceder espaços a dúvidas sobre o teor da teoria generalista que abarca o sistema processual pátrio, o professor Cândido Rangel Dinamarco assevera que tal estudo representa uma:

Síntese indutiva do significado e diretrizes do direito processual como sistema de institutos, princípios e normas estruturados para o exercício do poder, segundo determinados objetivos: passar dos campos particularizados do processo civil, trabalhista ou penal (administrativo, legislativo e mesmo não estatal) à integração de todos eles num só quadro e mediante uma só inserção no universo do direito é lavor árduo $e$ incipiente, que a teoria geral do processo se propõe a levar avante (Dinamarco, 1996, p. 59). 
Apesar de deter, em primeira análise, notável generalização e difundir-se amplamente pela ciência jurídica, percebe-se que cada ordenamento jurídico, em razão da especificidade de matérias contempladas, apresenta particularidades dispensadas pelo seu próprio sistema processual, sendo este um fenômeno identificado nos estudos da sistemática processual trabalhista. Considerados o caráter e as singularidades do sistema processual inerente ao universo jurídico trabalhista, Carlos Henrique Bezerra considera que:

A teoria geral do direito processual do trabalho tem objeto mais delimitado, porquanto investiga setores específicos do processo do trabalho, as suas estruturas peculiares, os conceitos próprios e os valores especiais almejados pelo direito material do trabalho. Sua finalidade primordial reside, portanto, na realização dos escopos social, político e jurídico do processo, sob a perspectiva do direito material do trabalho, bem como, por força da EC n. 45/2004, no que couber, de outros ramos do direito material, como o direito civil, o direito administrativo, o direito penal etc (Leite, 2017, p. 65).

No campo processual trabalhista, assim como ocorre nos diversos outros sistemas processuais, tem-se que é imprescindível que as normas processuais atuem em inequívoco com as normas preceituadas pelo Estado Democrático de Direito, provindo das supremas normas constitucionais. Com esse dever precípuo de consonância havido entre direito processual e ditames constitucionais, desenvolve-se a ideia de Direito Constitucional Processual. De acordo com os ensinamentos do doutrinador supra citado, este ideal:

Tem como ponto de partida nos princípios constitucionais do devido processo legal/justo e do acesso à justiça e se desenvolve por meio de outros princípios constitucionais e infraconstitucionais referentes às partes, ao juiz, à advocacia, à Defensoria Pública e ao Ministério Público, como os princípios do juiz e promotor naturais, do contraditório, da proibição das provas ilícitas, da publicidade dos atos processuais, da fundamentação das decisões, da efetividade, servindo, pois, de base para a aplicabilidade e a hermenêutica de todo o sistema processual brasileiro (Leite, 2017, p. $65)$.

Com a efetivação do Direito Constitucional Processual, percebe-se que a Constituição Federal, ao ocupar o patamar de norma suprema do ordenamento jurídico pátrio, se torna o parâmetro de interpretação mais adequado para ramos jurídicos do Direito, com destaque para o direito material e processual trabalhista. Nesse contexto, o mesmo doutrinador referenciado alhures expõe que:

Os métodos modernos de interpretação constitucional são perfeitamente aplicáveis ao direito do trabalho, mormente pelo fato de que este ramo possui inúmeras normas (regras, princípios e valores) positivadas na Constituição Federal de 1988, o que autoriza, inclusive, a afirmação da existência de um autêntico direito constitucional do trabalho. Além disso, os direitos fundamentais sociais dos trabalhadores encontram-se não raro em colisão com o direito fundamental de propriedade do empregador, o que exige do intérprete a adoção da metodologia interpretativa do texto constitucional (Leite, 2019, p. 171).

Findada a necessária exposição e o diálogo com o texto constitucional, percebe-se que o direito processual trabalhista figura como um instrumento que objetiva o "acesso à justiça de pessoas humanas e entidades empresariais e institucionais públicas e privadas vinculadas ao mundo do trabalho, normatizando, ademais, a estrutura e o fluxo do processo judicial de competência da Justiça do Trabalho". Destarte, os papéis aos quais se prestam o Direito Individual e Coletivo do Trabalho, como a implementação de princípios humanísticos e sociais, ao exemplo da equidade material entre as partes, e a efetivação de regras essencialmente democráticas, devem ser assegurados pelas normas processuais justrabalhistas.

De forma bastante infortuna, o que se nota com o advento da Lei 13.467/2017 é que todas essas premissas em que se baseiam o universo jurídico trabalhista tratam-se de mera utopia, se prestando tão somente a integrar os preceitos deontológicos do Direito, ou seja, apenas apontam como deveriam ser as normas do direto processual trabalhista. Neste flagrante cenário de contradição entre deontologia e ontologia jurídica, o brilhante Matheus Godinho explicita que: 
As preocupações e objetivos centrais da Lei da Reforma Trabalhista, entretanto, são de natureza sumamente diversa, centrando-se na ideia de restringir, ao máximo, o acesso à jurisdição pela pessoa humana trabalhadora, além de restringir a transmutação do processo judicial laboral em tortuoso calvário de riscos e apenações a essa pessoa humana, Trata-se, sem dúvida, de um constrangedor complemento à lógica das mudanças promovidas pela lei nos campos do Direito Individual do Trabalho e Direito Coletivo do Trabalho, agora dirigidas ao Direito Processual Trabalhista. E nessa direção processual trabalhista, a nova lei evidencia uma estrutura concertada e brandida no sentido de comprometer o patamar civilizatório processual garantido pela Constituição da República e pelo Direito Processual do País às pessoas humanas simples e destituídas de poder e de riqueza na realidade brasileira (Delgado, 2017, p. 48).

Expostos estes ilógicos e contrastantes fatos, percebe-se que a Reforma Trabalhista abala várias estruturas antes sedimentadas pelas normas trabalhistas. Dentre tantas, destaca-se as que são pertinentes à esta obra jurídica, quais sejam os impactos que a nova lei trabalhista provoca ao basilar instituto da justiça gratuita, culminando no consequente abalo ao acesso à jurisdição, também fundamental princípio constitucional, que encontra-se mitigado em razão da gigantesca insegurança jurídica que agora o reveste.

\subsection{Dos direitos constitucionais na seara justrabalhista}

A Constituição da República Federativa do Brasil, promulgada ao ano de 1988, também por vezes alcunhada como a “Constituição Cidadã”, é revolucionária ao incorporar, à matriz jurídica brasileira, o conceito de direitos fundamentais da pessoa humana, intrinsecamente atrelado ao ideal de sedimentar o Estado Democrático de Direito no país. Ressalta-se que esta concepção humanística revelada pela Constituição assenta-se a partir do teor dos artigos $1^{\circ}$ ao 17 do texto constitucional. Dentre os inúmeros parâmetros fundamentais supra mencionados, destacam-se dois deles, contidos no Título II, "Dos Direitos e Garantias Fundamentais", artigo 5 ${ }^{\circ}$, incisos XXXV e LXXIV, que tratam, respectivamente, do amplo acesso à jurisdição e do princípio da assistência jurídica integral e gratuita, os quais se encontram, hodiernamente, em muito prejudicados e mitigados em função da Reforma Trabalhista.

\subsubsection{Os princípios do amplo acesso à justiça e da assistência jurídica integral e gratuita}

O teor do texto constitucional é inovador ao prever um novo modelo atuação estatal, que denota uma nítida aproximação havida entre o ente estatal e a sociedade, qual seja o Estado Democrático de Direito. Nesse contexto revolucionário, a professora Ada Pellegrini Grinover expõe que "pode-se dizer, pois, sem exagerar, que a nova Constituição representa o que de mais moderno existe na tendência universal rumo à diminuição da distância entre o povo e a justiça". É nesse cenário de relevância social que surge o princípio do amplo acesso à jurisdição (art. $5^{\circ}, \mathrm{XXXV}$ ), em muito relacionado com o princípio da assistência jurídica integral e gratuita (art. 5, LXXIV).

O princípio do acesso ao judiciário, também conhecido como a inafastabilidade da jurisdição, é um direito básico e fundamental do qual dispõe o cidadão, o qual, como já exposto, é consagrado pelo art. $5^{\circ}$, XXXV, da Constituição Federal, ao expor, ipis literis, que “a lei não excluirá da apreciação do Poder Judiciário lesão ou ameaça a direito”. Destarte, tal dispositivo constitucional atua como um instrumento para efetivação do direito de análise judiciária de supostas lesões ou ameaças aos sujeitos de direito. Em meio a discussões doutrinária acerca do tema, este direito pode ser visualizado sob uma égide formal e material. Formalmente, esse direito trata-se da faculdade de principiar uma demanda judicial que objetiva a preservação de um direito, já em uma perspectiva material, tem-se que este direito representa uma garantia de integrar uma relação processual e ser beneficiado com decisões justas e retilíneas.

O princípio da assistência jurídica integral e gratuita fundamenta-se no estatuído pela Constituição Federal em seu art. $5^{\circ}$, LXXIV, ditando que: “o Estado prestará assistência jurídica integral e gratuita aos que comprovarem insuficiência de recursos”. A mencionada assistência jurídica, prevista pelo ordenamento jurídico constitucional e regulamentada pela Lei 1.060/90, consubstancia-se pela orientação e consultoria jurídicas, auxílio extrajudicial e também pela representação judicial, e 
é instrumentalizada pela atuação da Defensoria Pública, Promotorias e Conselhos Tutelares. Na questão atinente ao caráter gratuito desse assistencialismo, tem-se que os ônus e os custos inerentes à demanda judicial serão custeados pelo Judiciário, ou, em casos específicos, como na questão trabalhista, assim será feito pelo órgão representativo de classe laboral integrado pelo trabalhador a ser representado, como aduzido pelo art. 14, da Lei 5.584/70.

Com o exposto, percebe-se, porquanto, que tais direitos representam um parâmetro basilar de possibilidade de ingresso e representação judicial sobre o qual se apoia o cidadão nacional, sem o qual, indubitavelmente, o mesmo notar-se-ia sem perspectiva de projeção no Judiciário, e, por conseguinte, não o seria facultado a tutela e preservação de seus direitos e interesses. O que se percebe, de forma infortuna, é que a Reforma Trabalhista de 2017 atuou, não na esperada progressão e resguardo destes direitos, mas tão somente da mitigação e enfraquecimento destes princípios tão íntimos e basilares do Estado Democrático de Direito implementado, ao menos formalmente, pela Constituição. Assim sendo, tal reforma sedimentou, em seu grau mais explícito, um caminho pautado na "direção regressiva, excludente, desigual e segregacionista".

\subsection{Dos efeitos do novo paradigma do artigo 791-A sobre da justiça gratuita e o jus postulandi}

Um dos pontos mais atacados e distorcidos pela Lei 13.467 de 2017 trata-se da gratuidade processual, e isso se dá, em muito, pela nova norma estatuída acerca dos honorários advocatícios no interim do processo trabalhista, ao teor do art. 791-A da CLT. Em período anterior à reforma, a CLT não versava, ao menos explicitamente, sobre o pagamento de honorários advocatícios sucumbenciais nas ações disciplinadas pela lei trabalhista. Ocorre que, antes do advento do novo art. 791-A da CLT, vigorava a possibilidade de os empregados e empregadores demandarem judicialmente sem a necessidade de um advogado postulante para representa-los em juízo. Versava o art. 791, caput, e parágrafos s ipis litteris, que:

Art. 791 - Os empregados e os empregadores poderão reclamar pessoalmente perante a Justiça do Trabalho e acompanhar as suas reclamações até o final.

$\S 1^{\circ}$ Nos dissídios individuais os empregados e empregadores poderão fazer-se representar por intermédio do sindicato, advogado, solicitador, ou provisionado, inscrito na Ordem dos Advogados do Brasil.

$\S 2^{\circ}$ Nos dissídios coletivos é facultada aos interessados a assistência por advogado.

$\S 3^{\circ} \mathrm{A}$ constituição de procurador com poderes para o foro em geral poderá ser efetivada, mediante simples registro em ata de audiência, a requerimento verbal do advogado interessado, com anuência da parte representada.

Pelo prisma teleológico, o pretendido pelo legislador com este finado dispositivo legal era a perpetuidade da gratuidade processual, culminando, porquanto, num adequado e possível acesso à jurisdição, o que, em tese, seria dificultado caso fosse imprescindível a presença e representação advocatícia. Tal objetivo era tão fundamental no universo justrabalhista que, em constantes oportunidades, era ascendido ao patamar de princípio, e, nesse sentido, Mallet et al, conforme assinalado em decisão do TRT, da 4ª Região, na qual figurou como relatora a excelentíssima sra. Vânia Mattos, dita que "por exemplo: 'descabem honorários de sucumbência relativamente a parte não assistida por procurador credenciado pelo sindicato da categoria, sucumbente em parte na ação, já que viola princípio da gratuidade do Processo do Trabalho"”.

Ao início da vigência da CLT, inconteste é que a Justiça do Trabalho lidava com demandas das simples, sem demasiados aspectos técnicos, todavia, como é esperado do dinamismo humano e laboral, tem-se que a simplicidade ora experimentada cedeu espaço para questões mais complexas e profundam, intrínsecas ao conhecimento técnico. Neste cenário, então, a presença de advogado tornou-se quase um mandamento, pois, neste contexto, a parte desassistida por advogado faceia um grande risco de condenar a sua pretensão ao fracasso em função de desconhecimento específico atinente à área. Assim sendo, com imensa 
precisão, o Tribunal Superior do Trabalho, em julgado publicado em 01/04/2011, no qual figurou como relator o excelentíssimo Ministro João Oreste Dalazen, asseverou que:

Sob um prisma psicológico, sem o concurso do advogado, a parte louva-se do processo para um desabafo sentimental pouco produtivo; obcecada pela paixão e pelo ardor, não tem, como regra, a serenidade para captar os pontos essenciais do caso para melhora resguardo dos seus interesses, ao passo que o advogado, sem rancores pessoais, garante uma defesa mais persuasiva e eficaz (TST, 2011).

Ante a essa conjuntura de progressiva complexidade das demandas judiciárias trabalhistas culminando em conveniente e prudente representação advocatícia dos litigantes, irrompe o art. 791-A da Reforma Trabalhista, prevendo o encargo de pagamento de honorários advocatícios pelas partes no processo trabalhista, sem, contudo, excluir a possibilidade de a parte exercer seu jus postulandi por si só. Na questão atinente às hipóteses em que são devidos os honorários ao advogado, há duas grandes regras, distintas, que condicionam o seu pagamento, sendo tais a regra inglesa e a regra americana. De acordo com a primeira regra, o integrante do polo vitorioso da demanda deve ter seus gastos dispendidos com seu advogado repostos pelo perdedor da assim, o qual deverá arcar com os honorários advocatícios da outra parte, por outro lado, o segundo regramento determina que cada parte processual arcará com seus próprios gastos advocatícios. Tendo como pressupostos a previsão constitucional afirmando a indispensabilidade do advogado à administração da justiça (art. 133) e a restrição do pagamento dos honorários advocatícios, ainda que se trate de beneficiário da justiça gratuita, às demandas em que o autor estivesse assistido por sindicatos (art. 14, Lei 5.584/70) ou às ações e recursos que tornem obrigatória a presença do advogado (súmula 425, TST), indiscutível é que o processo trabalhista nacional acolheu e aplicou a regra americana.

De forma incongruente, o art. 791-A da CLT, ao delegar como hipótese generalizada o pagamento de honorários advocatícios sucumbenciais, rompe com a regra ora adotada, e cria um novo paradigma a ser enfrentado pelo litigante que esteja sob o pálio da justiça gratuita. Em termos simples e sucintos, proferidos por autores da Revista do TRT da $3^{\text {a }}$ Região, a inclusão no novo dispositivo legal exposto alhures "modificou substancialmente a sistemática de pagamento dos honorários de sucumbência, de forma a admitir a responsabilização do reclamante pelo seu pagamento mesmo quando estiver sob o pálio da justiça gratuita”. Nesta conjuntura arquitetada pela Reforma Trabalhista de 2017, é indiscutível que o processo trabalhista foi um muito afetado, perdendo a proteção que antes delegava ao beneficiário da justiça gratuita, justamente pelo fato de ter havido uma clara relativização a este instituto. Para perfeita elucidação da temática, a transcrição ipis litteris do artigo em comento é imprescindível:

Art. 791-A. Ao advogado, ainda que atue em causa própria, serão devidos honorários de sucumbência, fixados entre o mínimo de 5\% (cinco por cento) e o máximo de $15 \%$ (quinze por cento) sobre o valor que resultar da liquidação da sentença, do proveito econômico obtido ou, não sendo possível mensurá-lo, sobre o valor atualizado da causa $\S 1$ o Os honorários são devidos também nas ações contra a Fazenda Pública e nas ações em que a parte estiver assistida ou substituída pelo sindicato de sua categoria.

$\S 2$ o Ao fixar os honorários, o juízo observará:

I - o grau de zelo do profissional;

II - o lugar de prestação do serviço;

III - a natureza e a importância da causa

IV - o trabalho realizado pelo advogado e o tempo exigido para o seu serviço

$\S 3^{\text {o }} \mathrm{Na}$ hipótese de procedência parcial, o juízo arbitrará honorários de sucumbência recíproca, vedada a compensação entre os honorários. 
$\S$ 4o Vencido o beneficiário da justiça gratuita, desde que não tenha obtido em juízo, ainda que em outro processo, créditos capazes de suportar a despesa, as obrigações decorrentes de sua sucumbência ficarão sob condição suspensiva de exigibilidade e somente poderão ser executadas se, nos dois anos subsequentes ao trânsito em julgado da decisão que as certificou, o credor demonstrar que deixou de existir a situação de insuficiência de recursos que justificou a concessão de gratuidade, extinguindo-se, passado esse prazo, tais obrigações do beneficiário.

$\S 5$ São devidos honorários de sucumbência na reconvenção.

Transcrito o texto legal, percebe-se que a grande polêmica explicitada ganha forma ao longo de todo o dispositivo legal, porém, a essência do debate reside no teor do $\S 4^{\circ}$ do artigo. Ao expor de forma clara o seu intento, o $\S 4^{\circ}$ do art. 791 -A determina que:

Quanto aos honorários advocatícios sucumbenciais, caso o reclamante não obtenha sucesso nas pretensões condenatórias em numerário suficiente para arcar com honorários do advogado da parte adversa, as obrigações decorrentes da sucumbência ficarão sob condição suspensiva de exigibilidade e somente poderão ser executadas se, nos dois anos subsequentes ao trânsito em julgado da decisão que as certificou, o credor demonstrar que deixou de existir a situação de insuficiência de recursos que justificou a concessão da gratuidade. Após o prazo de dois anos, extinguemse as obrigações do beneficiário (Revista trt $3^{\text {a }}$ Região, 2017, p. 36).

De forma objetiva, Vólia Bomfim Cassar, ao dar explicações acerca do mesmo parágrafo, leciona que:

O beneficiário da gratuidade de justiça também deverá pagar os honorários advocatícios, que serão arcados pelos créditos que ganhou naquele ou em outro processo. Se não houver credito a receber suficiente para pagar o advogado ex adverso, a obrigação só será extinta se o credor não conseguir provar que, após dois anos (época em que a exigibilidade dos honorários fica suspensa), a situação de hipossuficiência econômica deixou de existir. A regra e similar àquela prevista no art. 98 do CPC, estando a diferença no prazo, pois no CPC o prazo de suspensão e de cinco anos e no processo do trabalho e de dois anos (§ 30 do art. 98 do CPC) (Cassar, 2017, p.100).

Partindo da premissa de que o disposto pelo conjunto normativo do art. 791-A tem o condão de obstar a materialização de princípios constitucionais fundamentais, ao relativizar a garantia da assistência judiciária gratuita e o amplo acesso à jurisdição, em 28/08/201 foi ajuizada a Ação Direta de Inconstitucionalidade nº 5766, pelo Procurador Geral da República, da qual transcreve-se alguns tópicos, em muito, pertinentes:

A Constituição de 1988 consagra a garantia de amplo acesso à jurisdição no art. $5^{\circ}$, XXXV e LXXIV, que tratam dos direitos a inafastabilidade da jurisdição e a assistência judiciária integral aos necessitados. Na contramão dos movimentos democráticos que consolidaram essas garantias de amplo e igualitário acesso à justiça, as normas impugnadas inviabilizam ao trabalhador economicamente desfavorecido assumir os riscos naturais de demanda trabalhista e impõe-lhe pagamento de custas e despesas processuais de sucumbência com uso de créditos trabalhistas auferidos no processo, de natureza alimentar, em prejuízo do sustento próprio e do de sua família.

[...]

Ao impor maior restrição à gratuidade judiciária na Justiça do Trabalho, mesmo em comparação com a Justiça Comum, e ao desequilibrar a paridade de armas processuais entre os litigantes trabalhistas, as normas violam os princípios constitucionais da isonomia (art. $5^{\circ}$, caput), da ampla defesa (art. $\left.5^{\circ}, \mathrm{LV}\right)$, do devido processo legal (art. $5^{\circ}$, LIV) e da inafastabilidade da jurisdição (art. $\left.5^{\circ}, \mathrm{XXXV}\right)$.

Em meio a esse claro descompasso havido entre o art. 791-A da CLT e os preceitos e intentos constitucionais, são de uma precisão cirúrgica os ensinamentos dados pelo grande Carlos Henrique Bezerra Leite, prezando pela formação de uma nova mentalidade finalística do judiciário e jurisdicionado, ao ditar que: 
É preciso que as inteligências tenham como norte a efetivação do acesso - individual e metaindividual - dos fracos e vulneráveis, como consumidores, trabalhadores, crianças, adolescentes, idosos, os excluídos em geral, não apenas ao aparelho judiciário e à democratização das suas decisões, mas, sobretudo, a uma ordem jurídica justa. Para tanto, é condição necessária a formação de uma nova mentalidade que culmine com uma autêntica transformação cultural não apenas dos juristas, juízes e membros do Ministério Público e demais operadores jurídicos, mas, também, dos governantes, dos empresários, dos trabalhadores, dos ambientalistas e dos sindicalistas (Leite, 2017, p. 60).

\section{Considerações Finais}

Este trabalho, conforme aludido em tópico inaugural, prontificou-se a prestar esclarecimentos de assuntos que revestem a reforma trabalhista, e, ao se pautar na paradoxal incongruência de tal alteração legislativa em relação aos parâmetros constitucionais. Assim sendo, foram elencados elementos da natureza da reforma trabalhista, destacando-se, especificamente, o art. 791-A da nova norma trabalhista e o seu consequente novo paradigma criado, tão distante do ideal de Estado Democrático de Direito.

Partindo da premissa supra exposta, é possível afirmar que o referido dispositivo de lei possui uma natureza incongruente com o ideal da lei celetista, assim, esta obra demonstrou que o intento da lei 13.467/2017, com enfoque ao art. 791-A, delegou uma desagradável sequela à legislação trabalhista, alterando, em muito, a sua natureza protetiva, que representava a sua essência em tempos de outrora.

\section{Referências}

Souza, R. T. D., Amaral, M. L. D., Santos Júnior, R. F. C. D., \& Severo, V. S. (2015). CLT comentada pelos Juízes do Trabalho da $4^{a}$ Região. São Paulo: LTr. <https://livros-e-revistas.vlex.com.br/vid/artigos-791-798-691271441>.

Federal, S. S. T. (2018). ADI 5766. 6(10). <http://www.stf.jus.br/portal/processo/verProcessoAndamento.asp?incidente=5250582>.

do Brasil, S. F. (1988). Constituição da república federativa do Brasil. Brasília: Senado Federal, Centro Gráfico. <https://www2.senado.leg.br/bdsf/bitstream/handle/id/518231/CF88_Livro_EC91_2016.pdf>.

Gabinete, B. T. S. D. T. T., da Presidência, G. P., \& Tribunal, B. T. S. D. T. T. (2016). Resolução n. 204 , de 15 de março de 2016. Resolução n. 204 , de 15 de março de 2016, (204). <http://www.tst.jus.br/>.

Cassar, V. B., \& Borges, L. D. (2017). Comentários à reforma trabalhista. Método.

Silva, H. B. M. D. (2017). Comentários à reforma trabalhista. Revista dos Tribunais, 1.

Alexandre Victor Silva, P., Esther Castro, R., \& Pedro Emílio Amador, S. (2020). Licitação pública: A importância do procedimento na transparência e combate a vícios em atos administrativos. Revista Multidisciplinar do Nordeste Mineiro, 2.

Delgado, M. G., \& Delgado, G. N. (2018). A reforma trabalhista no Brasil: com os comentários à Lei n. 13,467/2017. LTr.

Dinamarco, C. R. (1996). A instrumentalidade do processo. Malheiros Ed. Gonçalves, R. A. C. (2014). Apontamentos sobre o princípio do acesso à Justiça e o caso de prévio requerimento nas ações para concessão de benefícios previdenciários. Jus Navigandi. Oliveira.M.A., M. A. d. O., Freitas.F.S., F. d. S. F., \& Pereira.M.J.B., M. J. B. P. (2019). O princípio da proteção integral da criança e do adolescente diante da suspensão ou destituição do poder familiar. Revista Multidisciplinar do Nordeste Mineiro, 2.

Cintra, A. D. A., Grinover, A. P., \& Dinamarco, C. R. (1999). Teoria geral do processo.

Humbert, G. L. H. A Constituição, a garantia fundamental ao acesso à Justiça e a assistência judiciária gratuita. Estudo de caso. Jus Navigandi, Teresina, ano, 11. <https://jus.com.br/artigos/9401/a-constituicao-a-garantia-fundamental-ao-acesso-a-justica-e-a-assistencia-judiciaria-gratuita> .

Leite, C. H. B. (2019). Curso de Direito do Trabalho-11 ${ }^{a}$ Edição 2019. Saraiva Educação SA.

Leite, C. H. B. (2017). Curso de direito processual do trabalho. Saraiva Educação SA.

Mallet, E., \& Higa, F. D. C. (2017). Os honorários advocatícios após a reforma trabalhista. Os honorários advocatícios após a reforma trabalhista.

Vargo, J. F. (1992). The American Rule on Attorney Fee Allocation: The Injured Person's Access to Justice. Am. UL Rev., $42,1567$.

Trabalho, B. T. R. (2017). Revista do Tribunal Regional do Trabalho da $3^{\text {a }}$ Região:(nov. 2017). Edição especial. Revista do Tribunal Regional do Trabalho da $3^{a}$ Região:(nov. 2017). Edição especial. 